\title{
NUCLEAR DIFFERENTIATION IN THE POLLEN GRAIN
}

\author{
By L. F. LA COUR \\ John Innes Horticultural Institution, Hertford, Herts. \\ 1. INTRODUCTION \\ Received 6.ii. 49
}

THE satisfactory differentiation of the pollen grain is necessary for its effective life, and therefore directly bears on all breeding experiments with flowering plants. Moreover it is under a genetic control of a most complex kind, derived partly from the diploid parent and partly from the haploid cell itself, where it is the most sensitive indicator of the effects of segregation. For these various reasons a precise understanding of the physiology of its development is needed by the plant breeder.

A wealth of evidence has accumulated in support of the belief that nuclear differentiation in the pollen grain of Angiosperms is dependent on polarity of development. The most notable work in this direction has been done by Sax (1935), Sax and Husted (1936) and Geitler (1935). Notwithstanding the excellence of this work, some of the underlying principles have remained obscure.

In the present work, the initial observations were connected with an anomalous behaviour found in dwarf pollen grains of a single clone of Tradescantia bracteata. From information so gained, and by comparison with other material, it is believed that a plausible explanation for nuclear differentiation has been provided. In order that the problem should be seen in clear perspective, a review of the previous relevant literature is included.

\section{SURVEY OF PREVIOUS WORK}

\section{(i) Formation of the pollen grain}

The formation of the pollen grains, and their arrangement in the tetrad, is effected by the two meiotic divisions. It is generally accepted that the two second divisions in most monocots occur after the firstdivision wall is formed and on axes perpendicular to the first. Where the two axes are in one plane, the four nuclei are arranged in the same plane, with the pollen grains meeting along one diameter of the mother cell.

This mode of formation, which we may call type I, is of the kind ascribed to the diploid species of Tradescantia examined by Sax and Edmonds (1933), Sax and Husted (1936) and Johnson and Peck 
(1937). The last, however, describe in one-fifth of the cells (or one-half in Rhoeo discolor) an alternative kind of tetrad formation which, although not mentioned, was doubtless seen by $\operatorname{Sax}$ and his collaborators. It is derived from the two spindles at the second division being in axes at right angles to each other. It was concluded, that this less frequent type of division, which we may call type II, was localised in small sectors of the anthers.

In a more recent contribution, Vogl (1947) has surveyed the different kinds of tetrad formation seen in various monocots. She finds that there is very generally, some deviation from the two kinds of second-division behaviour just described. Cells occur, in which the two spindles are orientated at intermediate angles, to give intermediate kinds of tetrad formation between types I and Il. She concludes that spindle orientation is influenced by cell shape, cell pressure, size of the spindle in relation to cell size, and sometimes by " internal cytoplasmic action."

In the tetrads of dicots, a tetrahedral arrangement of cells is commonly found. It arises from the two second divisions taking place in planes at right angles to each other as in type II of the monocots, but with partitioning of the cytoplasm simultaneously with completion of the two meiotic divisions. Such an arrangement occurs in some species of monocots, e.g. in Gasteria and Alö̈ (Johnson and Peck, 1937).

\section{(ii) Development of the free pollen grain}

Normally, in most Angiosperms, the pollen grains are released from the tetrad before they undergo mitosis. Exceptions to this common behaviour, are found in most of the Ericacea, e.g. Erica persoluta (Geitler, 1935); all members of the Juncacea, e.g. Luzula purpurea (Malheiros, Castro and Câmara, 1947) ; Elodea (Wylie, r 904) and Salpiglossis sinuata (Wodehouse, 1935). In the Orchidacee, in some species, the pollen grains are found in tetrads while, in others, several hundred pollen grains remain in packets which are loosely united to form the pollinium (Barber, 1942). A similar situation to the last occurs in the Mimosacee and Asclepiadacea.

With few exceptions, a vacuole arises early in development, toward one end of the pollen grain, ( $c f$. Wulff and Maheshwari, 1938). Vacuole formation is normally absent in Luzula purpurea (Malheiros, et al., 1947) and in some species of Haworthia (Dr Pinto Lopes, personal communication). In the last species, a dense mass of cytoplasmic granules, may possibly as we shall see, have the same effect.

In Tradescantia the activity of the vacuole appears to be closely connected with the disappearance of the cytoplasmic granules. These range from about $0 \cdot 5^{-1} \mu$ in diameter and are thought to be of a protein nature. They occur at meiosis and, persist in the pollen grain, till formation of the vacuole (Sax and Edmonds, I933).

The presence of the vacuole leads to a migration of the nucleus 
and a confinement of most of the cytoplasm to one end of the cell. In some species, however, there may be a further movement of the cytoplasm and nucleus, prior to pollen-grain mitosis. This happens where the dorsal wall, originally the inner wall in the tetrad, flattens out, e.g. in Tradescantia (Sax and Edmonds, 1933).

In these species following the first movement, and at about the time of early prophase, there is a movement of cytoplasm and vacuole, so that two vacuoles are formed; one at each end of the cell, with the bulk of the cytoplasm between them. The nucleus then lies central in the long axis of the cell, but toward the dorsal wall.

\section{(iii) The pollen-grain mitosis}

The position of the mitotic spindle, and its angle to the wall, is under normal conditions constant usually for a whole species and sometimes for a whole genus (Geitler, I935; Sax and Husted, 1936). The last-named believe, that with few exceptions, the spindle is at an angle of $45^{\circ}$ to the axes of both meiotic divisions.

The spindle is, as a general rule, short. It is also asymmetrical being closer to the side at which the generative nucleus will be cut off. This leads to a difference in arrangement of the chromosomes at the two poles. From the work of Brumfield (r94I) it is evident that the degree of asymmetry is associated with the position of the prophase nucleus, asymmetry being greater where the nucleus is flattened strongly on the side adjacent to the wall.

It is also evident that the degree of asymmetry can be variable, for Hagerup (1938) in Orchis maculata, found the metaphase spindles to be symmetrical but those of anaphase and telophase asymmetrical. On the other hand, Brumfield from observations in Allium, Pancratium and Tradescantia concluded that the degree of asymmetry decreased from metaphase to anaphase. My own observations in Tradescantia, as we shall see, show that at telophase the spindle is usually more asymmetrical than at anaphase. These observations also show that the shape of the spindle is influenced by vacuole formation, which we know, from the observations of Sax, is influenced by environment. There may thus be an explanation for the isolated claims that the spindle is symmetrical in some species ( $c f$. Maheshwari, 1949).

The spindle is also asymmetrical where it extends through the whole depth of the cytoplasm, as in Uvularia (according to Geitler's illustrations). Thus, irrespective of spindle length, asymmetry is doubtless responsible for the resulting cells being unequal $(c f$. Wulff and Maheshwari, I938).

From the work of Sax (1935) it is evident that the position of the generative nucleus, and indeed its differentiation, is governed by the position and angle of the mitotic spindle. Geitler (1935) has shown that the generative nucleus, in a large majority of species, is cut off 
towards the wall which was inmost in the tetrad. Reported departures from this behaviour, are :-
(i) Radial wall Allium
(ii) Outer wall Elodea
Vaccinium
Albizzia
Acacia
(iii) Facultative
Acanthus spinosus
Geitler, I 935
Wylie, I 904
Samuelsson, I 9 I 3
Maheshwari, I93 I
Newman, I 934
Drahowzal, I936

In Acanthus it can apparently be cut off, at either the inner, or outer wall. Likewise, in Periploca sepum the position varies, but this is attributed to the shape of the pollen mother cells influencing the direction of the second-meiotic divisions (Sax and Husted, 1936).

As Wulff and Maheshwari (1938) have pointed out, the germ pores and furrows often serve as useful markers. The exact position of the generative nucleus in many species must always remain obscure, owing to lack of markers. Its discovery is simplified of course, where the pollen grains remain united, naturally or unnaturally, in a common exine.

\section{(iv) Differentiation}

The nuclei.-The pollen mitosis normally leads to the formation of daughter nuclei with equal amounts of chromatin, but of unequal size. From the very beginning the generative nucleus is recognisable by its smaller size. Later the distinction is made doubly clear by a marked difference in staining capacity between the two nuclei. The vegetative nucleus, in expanding, gradually loses its affinity to react with basic dyes. Apparently Wulff (1933) was the first to show its weak reaction to Feulgen's reagent. The generative nucleus on the other hand reacts strongly. It is generally assumed therefore, that the vegetative nuclei lose their desoxyribose-nucleic acid.

The cytoplasm.--It is well established that the cytoplasm on the two sides diverges in regard to staining. The generative cell loses its affinity towards all stains. The vegetative cell gains in affinity. They thus diverge also from their own nuclei. The change in the vegetative cell was noted by Painter (1943) in Rhoeo discolor, who found that the cytoplasm of the mature pollen grain is rich in ribose-nucleic acid. He suggested that it accumulated in the pollen grains at the expense of the tapetal cells.

\section{(v) The effects of environment}

Sax (1935, I937, I942) has shown how nuclear differentiation is influenced by the environment: in Tradescantia, high and low temperatures induced the same end result: disturbed polarity and, consequently, failure of differentiation. In a triploid, unbalance likewise led to failure of differentiation. 
Similarly Koller (1943) in Tradescantia, has shown that irradiation before mitosis suppresses differentiation. He also found, that the staining capacity of micro-nuclei depended solely on their position at the end of telophase. They followed that of nuclei to whicli they were adjacent.

Associated with errors in differentiation, the most frequent event is the supernumerary division of the vegetative nucleus ( $c f$. Upcott, I939). Sax records Mrs Sax as having found in Picea a pollen grain with four equal-sized nuclei. There are, however, similar kinds of behaviour attributable to other causes. In Sorghum, Darlington and Thomas (1941) found pollen grains with extra divisions of the vegetative nuclei. But here extra division was influenced by the inclusion of heterochromatic chromosomes supernumerary to the basic set.

The generative nucleus may sometimes divide precociously, that is in the pollen grain instead of in the pollen tube (Upcott, I939). Following temperature shock it may likewise divide in the pollen grain, but without equational division of the chromosomes (Sax, 1937).

\section{MATERIALS AND METHODS}

The Tradescantia bracteata material consisted of four clones $\left(20^{1}\right.$, $2 \mathrm{I}^{2}, 2 \mathrm{I}^{3}$ and $22^{1}$ ) the remains of a collection provided by Dr L. F. Randolph in 1929. All clones regularly form six bivalents at meiosis. The following four plants were also examined for comparison: Tradescantia virginiana $(4 x), T$. canaliculata $(2 x) \times \mathrm{T}$. Hamburg $(4 x)$, Scilla sibirica $(2 x=\mathrm{I} 2)$ and Luzula purpurea $(2 x=6)$.

Apart from a few observations in acetic stains and sectioned material, the anthers were usually smeared and fixed in acetic alcohol ( $1: 3$ ). Fixation was limited to 30 minutes, but hardening was continued by leaving the smears in 95 per cent. alcohol overnight prior to staining.

Following hardening, slides were stained: (i) in methyl-green pyronin, (ii) in I per cent. toluidine blue, (iii) by Feulgen's reagent, with and without counter-staining in the acid dye Ponceau red RR, or (iv) in the acid dye alone. The acid-dye solution, was prepared in the way proposed by Hydén (1934) for the study of protein metabolism in nerve cells. The other methods have been described in detail by Darlington and La Cour (1947).

\section{DWARF POLLEN GRAINS}

A chance examination of anthers, from late buds (with bi-nucleate pollen grains) of the clone $20^{1}$ (which I shall refer to as the sensitive clone), revealed a number of delayed uninucleate grains regular in size, but approximately two-thirds the volume of normal pollen grains. Counts made from single anthers of different buds showed that they represented I5-25 per cent. of the total pollen grains. In each case the remainder being of regular size. Little difference in the proportion 


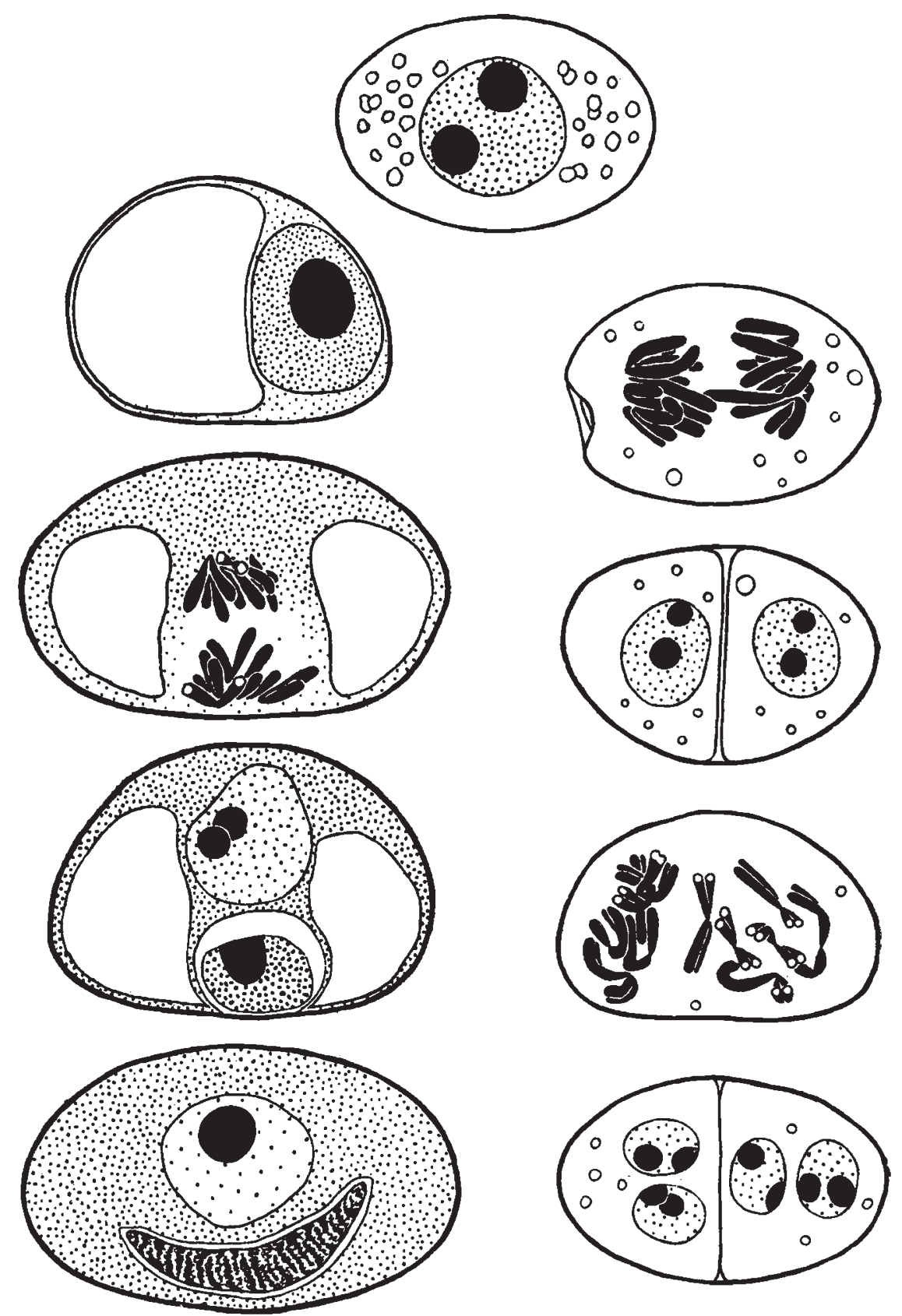

Fig. 1.-Stages in the development of normal and dwarf pollen grains in Tradescantia bracteata. Stippling indicates the concentration of protein and ribose-nucleic acid in the cytoplasm; desoxyribose-nucleic acid in the nuclei. The extra mitosis in the dwarf grains occurs only after temperature shock (see later in the text). $\times 1500$. 
of dwarf grains was found between individual anthers in a bud. Great variation was found between buds. These first counts were made at the end of the 1945 season. Since then proportions have been found as high as 40 per cent. but never lower than the 15 per cent. There are no intermediate grains.

At mitosis, the dwarf grains always show the normal chromosome number, $2 n=6$. At anaphase, however, the division is almost invariably lengthwise in the cell instead of crosswise. Following division, the cytoplasm usually divides equally between the two telophase nuclei, which remain of equal size and staining density. With Feulgen staining, they show the nucleic acid deficiency of typical vegetative nuclei. Mitosis in the dwarf grains, begins at about the time it ceases in the normal-sized grains, and only about 40 per cent. of them manage to divide before the anthers dehisce.

The difference in size between the two kinds of pollen grain is first conspicuous at the end of mitosis in the normal pollen grain. Earlier than this, the dwarf grains are noticeable only by the absence of the vacuole. A comparative history of the two types (fig. I) shows that vacuoles are never developed in the dwarf grains; .but they retain the cytoplasmic granules, with some diminution for the greater part of their life. Two other characteristic features become apparent later: (a) The dorsal wall is less distinct, giving the cells a more symmetrical shape than normal pollen grains. (b) The cytoplasm appears thin and, possibly because of this, the walls sometimes partially collapse with mounting in "Euparal."

How is the origin of these dwarf grains to be explained? First, the extreme variability in the proportion of such grains excludes the view that they result from the recombination and segregation of two segregating genetic differences. Secondly, an alternative view that they might result from the consequences of inversion crossing-over is also excluded. The frequency of inversion crossing-over varied in the reverse direction to the proportions of dwarf grains determined at the same time, as shown in table I, and was in any case far too low.

TABLE I

Frequency of inversion crossing-over in relation to the formation of dwarf pollen grains

\begin{tabular}{|c|c|c|c|c|c|c|c|c|}
\hline & $\begin{array}{l}\text { Total } \\
\text { cells }\end{array}$ & B & $\mathbf{B}+f$ & $f$ & $2 f f$ & Joint & $\begin{array}{c}\text { Inversion } \\
\text { crossing-over }\end{array}$ & $\begin{array}{c}\text { Dwarf } \\
\text { pollen grains }\end{array}$ \\
\hline I $945\left\{\begin{array}{l}\text { A I } \\
\text { A II }\end{array}\right.$ & $\begin{array}{l}213 \\
144\end{array}$ & $\begin{array}{l}5 \\
1\end{array}$ & $\begin{array}{l}5 \\
\cdots\end{array}$ & $\begin{array}{l}3 \\
2\end{array}$ & $\ddot{I}$ & 357 & 4.8 per cent. & I 5 per cent. \\
\hline I947) A I & $\begin{array}{l}203 \\
150\end{array}$ & $\begin{array}{c}3 \\
\cdots\end{array}$ & $\begin{array}{l}\mathrm{I} \\
\cdots\end{array}$ & $\begin{array}{l}\cdots \\
\cdots\end{array}$ & $\begin{array}{l}\cdots \\
\cdots\end{array}$ & 353 & $I \cdot I$ & 40 \\
\hline
\end{tabular}

In 1947 an attempt was made to grow the clone $20^{1}$ under controlled temperature conditions, in order to relate the effect of temperature 
with the dwarf-grain reaction. These experiments failed presumably because of incorrect lighting. After 3-4 days treatment cell development stopped ; the pollen mother cells would not progress beyond meiosis.

Pollen-grain counts were then made from plants in the field and a record made of dates on which the material was fixed. Comparison with meteorological records, shows that sensitivity to the production of dwarf grains seems at times to be influenced by drought and possibly also by high temperature (table 2).

TABLE 2

Frequency of dwarf grains in the sensitive clone $20^{1}$ in relation to weather conditions

\begin{tabular}{|c|c|c|c|c|c|c|c|}
\hline \multicolumn{4}{|c|}{ Period } & $\begin{array}{c}\text { Temperature } \\
\text { (over I2 days) }\end{array}$ & $\begin{array}{c}\text { Rainfall } \\
\text { (over I } 2 \text { days) }\end{array}$ & \multicolumn{2}{|c|}{$\begin{array}{c}\text { Dwarf } \\
\text { pollen grains }\end{array}$} \\
\hline I 945 & October. & & . & $\cdots$ & $\cdots$ & 15 & cent. \\
\hline I 947 & $\begin{array}{l}\text { to July I 2th } \\
\text { to September 2nd } \\
\text { to October roth } \\
\text { to October 2oth }\end{array}$ & . & $\dot{.}$ & $\begin{array}{l}6 \mathrm{I}-73 \\
72-8 \mathrm{I} \\
66-67 \\
54-59\end{array}$ & $\begin{array}{c}0.67 \text { in. } \\
\text { nil } \\
\text { ", in. }\end{array}$ & $\begin{array}{l}24 \\
35 \\
30 \\
41\end{array}$ & $\begin{array}{l}\text { ", } \\
\text { ", }\end{array}$ \\
\hline 1948 & $\begin{array}{l}\text { to August ist } \\
\text { to August I } 7^{\text {th }} \\
\text { to August 24th }\end{array}$ & . & $\dot{.}$ & $\begin{array}{l}69-94 \\
64-71 \\
64-72\end{array}$ & $\begin{array}{l}0 \cdot 08 \text { in. } \\
2 \cdot 0 \text { in. } \\
2 \cdot 3 \text { in. }\end{array}$ & $\begin{array}{l}4^{1} \\
34 \\
3^{8}\end{array}$ & $\begin{array}{l}\text { ", } \\
\text { ", }\end{array}$ \\
\hline
\end{tabular}

Included here, is one other observation on abnormal pollen-grain development which is worthy of note. Amongst a sample of pollen grains in Scilla sibirica, an anomalous case was found where four pollen grains had remained together in a tetrad. In three of them differentiation was complete. The fourth showed the consequences of derangement in polarity (fig. 2). It may also be mentioned that the pollen grains of this species contain numerous cytoplasmic granules, unlike those in Tradescantia, however, their activity appears in no way to be connected with that of the vacuole.

\section{ORIENTATION OF THE SECOND MEIOTIC SPINDLES}

The search for inversion bridges and fragments at meiosis in the clone $20^{1}$, revealed a proportion of second anaphase cells, with a spindle orientation similar to that reported by Vogl. By visual observation alone, the cells within an anther could be classified into three groups, as we saw earlier, types I, II, and intermediate. Comparison of $T$. virginiana, a triploid hybrid, and the other clones, revealed a difference in the proportions of the three types of cells. In the triploid the frequency of intermediate cells was much higher. No doubt in triploids, spindle orientation is influenced also, by unequal chromosome distribution.

It was first considered whether cells of the intermediate type 
might (together with the genotype of the sensitive clone) be held responsible for the origin of the dwarf grains. An attempt was then made, to detect by accurate means, any differences in spindle orientation that might occur between the clones.

By visual observation alone this is impossible. But if with a camera lucida, the focal points of the poles are projected, the angle between them can be determined, the unit readings on the fine adjustment providing the units of the co-ordinate system. It is essential to select only cells at late anaphase, and of equal development on both sides.

In this way, an analysis was made in clones $20^{1}$ and $2 \mathrm{I}^{2}$. The smear used for analysis of the clone $20^{1}$, was from material grown at $63^{\circ}-65^{\circ} \mathrm{F}$. Unfortunately the analysis was made out of season, and no temperature-controlled experiments had been undertaken with clones without dwarf grains.

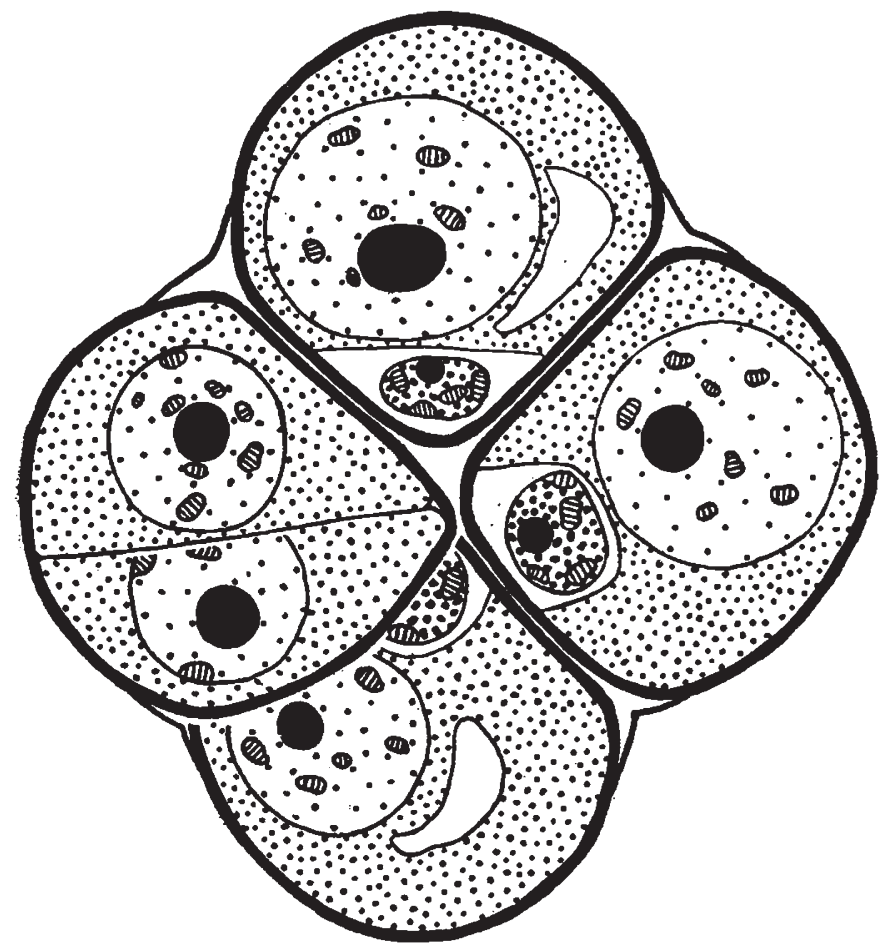

FIG. 2.-Anomalous coherence of pollen grains in Scilla sibirica, showing failure of differentiation in one grain through derangement in polarity of mitosis. Note, specificity in position of the generative nuclei. $\times 1300$.

The proportion of dwarf grains varied, from 15 per cent. in a sample of 1945 , to $4^{1}$ per cent. in a sample of 1948 . The proportion 
of intermediate type spindles was 17.4 per cent. for clone $20^{1}$ in the controlled temperature sample of 1947 , and 25.4 per cent. for clone $2 I^{2}$ at an uncontrolled temperature (fig. 3). The dwarf grains may therefore be derived from the intermediate type of cell with skew

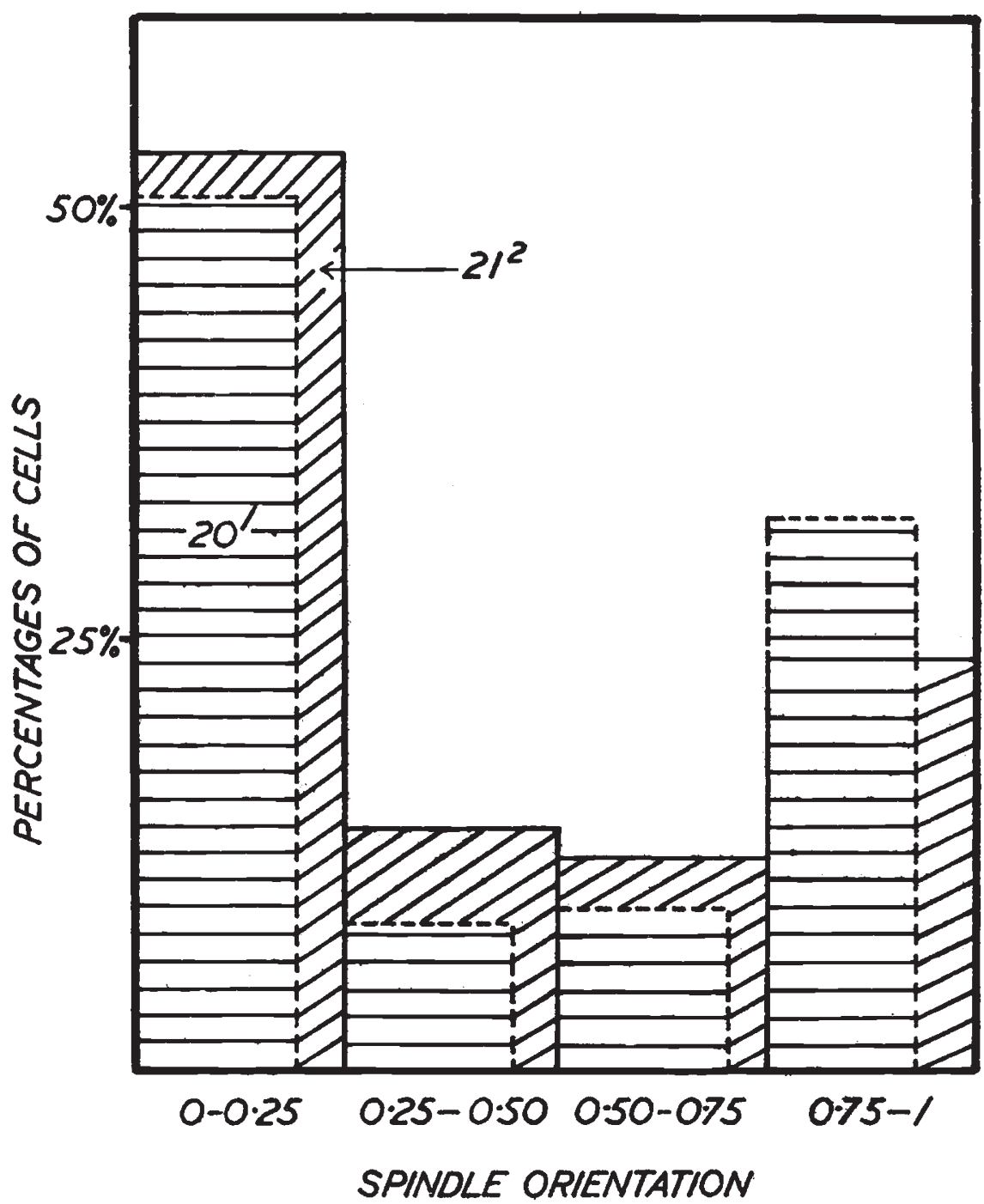

FIG. 3.-Graph showing an analysis of spindle orientation at the second meiotic anaphase in two clones of Tradescantia bracteata, obtained by measurement of the angle between spindles.

spindles, but controlled environmental observations, of the grains and the spindles, will have to be made together to test the hypothesis. Further information may be provided by breeding experiments, since some natural seedlings of the sensitive clone show the same sensitivity. 


\section{STAINING WITH PONCEAU RED AND METHYL-GREEN PYRONIN}

At first Ponceau red was used purely as a counter-stain, in order to render the cytoplasm and vacuoles clearly visible after staining with Feulgen. The unstained vacuoles and refractive granules, are then shown in relief against the pale-red staining cytoplasm. Staining in the dwarf grains, however, was almost absent.

Slides were then stained showing together all stages of development from meiosis to late pollen grains. In this way, I hoped to obtain an early difference in stainability of the cytoplasm, and hence to trace

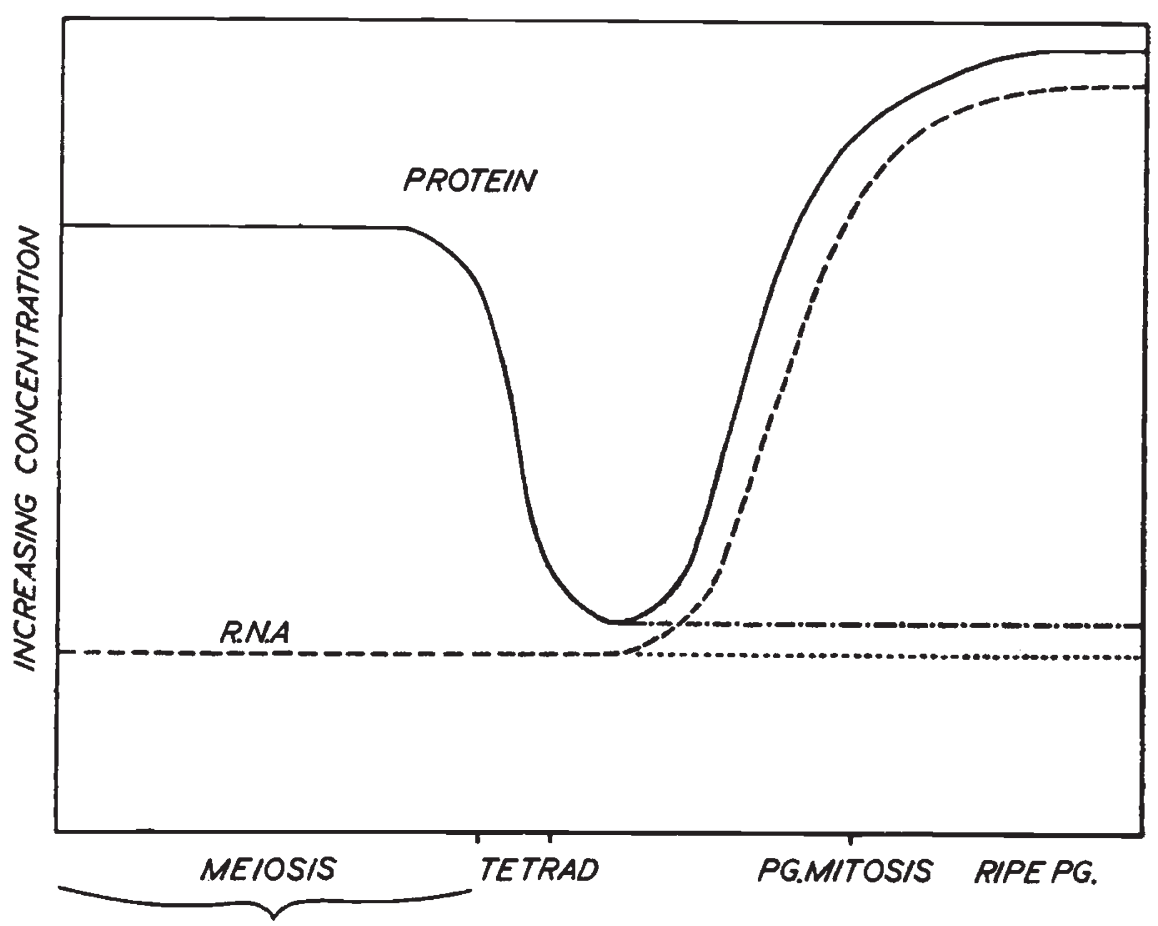

Frg. 4.-Graph showing the relationship between protein and nucleic acid concentration in the cytoplasm during the development of normal and dwarf pollen grains in Tradescantia bracteata.

the development of the dwarf grains back to its very origin. This I failed to do, but the results were interesting in connection with the staining of the cytoplasm at different stages of development. The stainability of the cytoplasm decreases at the time of the formation of the pollen grains, but increases correspondingly, with their growth and development. Similar results were obtained with Ponceau red alone as an acid stain. Similarly prepared slides were then stained in methyl-green pyronin in order to show the distribution of ribose-nucleic acid. The observations from both treatments are expressed in fig. 4 .

How are these differences in reaction to be interpreted? It would be unsafe to assume, that the differences found with the acid dye, imply differences in basic substances which are correlated with 
particular stages of development in the cell. It is safer to assume, since the reaction of any acid dye principally depends on adsorption, that the differences are connected with changes in density of the cytoplasm. These changes may possibly be connected with, in the first place, formation of the pollen grain, later with the growth and function of the free pollen grain. Staining with Ponceau red does, however, show one thing that appears to be certain. It shows that the dwarf grains are deficient in proteins.

Painter as we saw earlier, has suggested that ribose-nucleic acid is drawn by the pollen grain, from the tapetal cells. Sections of anthers in the clone $20^{1}$ show that the dwarf grains are not localised in position, but appear to be spread throughout the anther. That they do not accumulate ribose-nucleic acid in the same way as normalsized grains may seem remarkable. But Caspersson (1940) has shown elsewhere that ribose-nucleic acid accumulates only where protein activity is high. Thus it would seem, that the low level of ribose-nucleic acid in the dwarf grains is associated with the low level of protein production.

The observation also made clear another important aspect of nuclear differentiation. Following either methyl-green pyronin or toluidine-blue treatment it was obvious that no ribose-nucleic acid, or extremely little, is present in the cytoplasm confining the generative nucleus. A clear but not so marked difference was also seen with the acid dye, indicating some difference in protein concentration.

\section{NUCLEAR DIFFERENTIATION}

The pollen-grain mitosis normally leads to a distribution of cytoplasm whose inequality is both quantitative and qualitative. The knowledge that the qualitative inequality is one of ribose-nucleic acid provides a simple explanation for nuclear differentiation. The cytoplasm on the two sides is working in opposite directions. On one side, protein and ribose-nucleic acid activity is high : the function being one of growth. On the other, ribose-nucleic acid is negligible with protein activity presumably low: the function being one of further mitosis for sperm production.

The unequal distribution is relatable only to the mitosis. The most plausible explanation is provided by the apparent asymmetry of the spindle and seemingly, its control of spindle length. In the normal pollen grains of the clone $20^{1}$, the spindle seldom extends to the whole depth of the cytoplasm. From mid-anaphase to early telophase, the spindle normally becomes increasingly asymmetrical and shorter in length. In the dwarf grains, however, the spindle is almost invariably long, with the poles equidistant from the walls. The spindle is therefore never asymmetrical (fig. I, plate II).

In order to provide further evidence, material was examined, where failure of differentiation had been induced either by temperature 
or X-rays. The effect of both kinds of treatment on development, is as we saw earlier, closely similar. They lead to an upset in cell processes such that many pollen grains occur with incomplete vacuole formation at the time of mitosis. Phases are then available, intermediate between accomplishment and failure of differentiation. I then found that when the angle of spindle orientation was deranged through incomplete vacuole formation, the degree of asymmetry was lessened. The pole adjacent to the wall moved inwards. The consequences were clear: when the disturbance in polarity was not too severe, the cytoplasm could still be unequally divided, but nevertheless nuclear differentiation was incomplete. It failed, as we shall see, because the quality of the cytoplasm was not right (fig. 5, plate II).

Observations in Luzula purpurea showed what the quality should be. In this species the four primary nuclei remain in a tetrad. They are retained in the original pollen mother cell wall and partitioning of the cytoplasm does not happen until differentiation is complete. The four mitoses are not always in step, and it is possible to compare changes in the character of the cytoplasm, at slightly different stages of development within a single cell. To avoid sectioning, iron acetocarmine was used, but the accuracy of the observations was checked in methyl-green pyronin. No vacuoles are formed. The cytoplasm is extremely dense, and because of this, overstaining of the cytoplasm is difficult to avoid. Heavy staining, however, is necessary in order to trace the series of events.

Four clear zones are markedly noticeable in the cytoplasm. It is in these zones that the spindles are formed, following the dissolution of the nuclear membranes. From pro-metaphase onwards ribose-nucleic acid infiltrates into them. At anaphase the outer poles are almost enclosed. With completion of the division only the inner poles have escaped the invasion. These yield the generative nuclei : they remain in clear cytoplasm (plate I). Thus it is evident that the cytoplasm received by the generative nucleus is comprised solely, or mostly, of nuclear sap derived from the primary nucleus. It is also clear that partial differentiation is related to the degree of contamination from the granular cytoplasm.

That the whole process is so clear in Luzula, is probably due to the absence of inner walls. In Tradescantia and presumably in most other plants, the clear cytoplasm is compressed tightly against the wall. It is only after telophase, when the spindle has dissolved, that what has happened becomes clear.

\section{THE EFFECTS OF TEMPERATURE SHOCK}

Potted plants of $T$. bracteata, clone $20^{1}$, were kept at periods of I-6 hours at $38^{\circ} \mathrm{C}$. and then transferred to $-5^{\circ} \mathrm{C}$. for I-2 hours. With each experiment, the first observations were made after an interval of 24 hours following the treatment. 
Chromosome breakage was found once, and although severe, it was nevertheless confined to a single spike. The treated plants were examined periodically, however, in order to study the effects of the treatment on pollen-grain development. The observations revealed abnormalities similar to those found by Sax in his experiments. They included failure of differentiation in the normal large grains and anomalous division of vegetative nuclei.

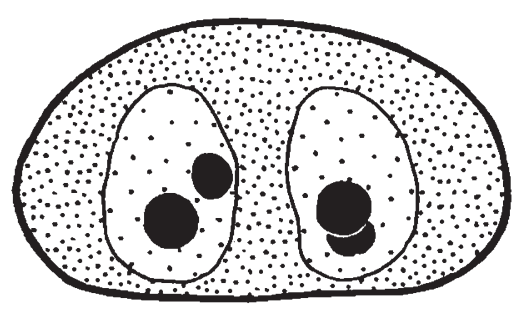

(a)

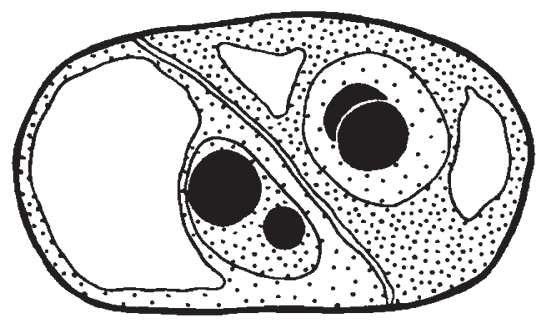

(b)

FIG. 5.-Pollen grains in Tradescantia bracteata after irradiation: (a) complete failure of differentiation, $(b)$ partial differentiation. Stippling of the cytoplasm indicates differences in protein as shown by Ponceau red. $\times 1500$.

In one sample, 20 days after treatment, some of the dwarf grains likewise, showed division of both daughter nuclei formed at the primary mitosis (fig. I). In some cells the two divisions were not always strictly in step. Similarly, in other cells, the divisions were dissimilar in orientation. More frequently, however, both divisions were in the short axis of the cell. Partitioning of the cytoplasm usually followed anaphase separation, giving, where the divisions were parallel, pollen grains resembling tetrads (plate II).

\section{CAUSAL SERIES OF VARIATIONS}

From the foregoing it is evident that nuclear differentiation is dependent on a polarity of pollen-grain contents. It is brought about by movements and changes in the character of the cytoplasm. The principles involved and the variations in development which occur can be defined as follows :-

I. Orientation of spindles at the second anaphase of meiosis.

2. In Tradescantia: the disintegration of cytoplasmic granules. Failure to disintegrate leads to failure of vacuole formation.

3. Development of vacuoles (possibly connected with the germ pores since they are formed adjacent to them) leads to a spatial restriction of the cytoplasm.

4. Position of the primary nucleus related to :-

(a) as in Haworthia, the position of the vacuole or where it is absent, to the cytoplasmic granules ;

(b) a wall, causing it to be eccentric. It lies towards the thick wall in most species with single pollen grains, e.g. Tradescantia; or in the centre of the pollen mother cell where the grains remain naturally united, e.g. Luzula. 
5. Differentiation of cytoplasm into (i) dense granular type rich in imported ribose-nucleic acid and (ii) clear fluid type which must largely be composed of nuclear sap.

6. (a) Spindle always arises from clear cytoplasm. Thus the clear type is converted into a third kind of fibrous cytoplasm.

(b) Its length and direction is determined by the position and shape of the clear region which, except in Luzula and some Haworthia species, is contingent on vacuole formation and subject to control by the granular cytoplasm. The propagation of the spatially restricted granular cytoplasm restricts its field by pressing it close to the wall or, as in Luzula, to the centre of the pollen mother cell. In Haworthia it is presumably governed in part by cytoplasmic granules (which lead to its confinement close to a wall) and by the granular cytoplasm. Thus in most species, absence or incompleteness of vacuole formation lead to the spindle being wrong in direction and length, e.g. Scilla the dwarf grains of Tradescantia and normal grains following temperature treatment.

7. The generative cell arises next to the wall in the clear, ribose-nucleic acidfree cytoplasm.

8. Yet the nucleus retains a full stock of desoxyribose-nucleic acid, while the vegetative nucleus lying in rich cytoplasm gives up its desoxyribose-nucleic acid.

9. The vegetative cell can divide again either where differentiation of the vegetative and generative cell breaks down, or with gene or chromosome upsets, or where the temperature upsets nucleic acid, protein, or enzyme conditions. The effect may be cumulative as in Sorghum with B chromosomes. Extra division does not then occur once, but many times; eventually it leads to death of the pollen grain.

I0. Precocious division of the generative nucleus, following upset in protein or enzyme conditions by temperature.

\section{THE CONTROL OF THE SPINDLE}

The control of the spindle length by restriction of the clear zone of cytoplasm, is also seen in the oöcytes of animals, where the spindles are invariably extremely short in relation to cell size. The zone of spindle formation is enclosed by granular cytoplasm much more dense than that of the pollen grain. There seems little doubt that it is responsible for the restriction of spindle length.

The pollen-grain observations throw light on another aspect of spindle formation, viz. the hollow spindles seen in white blood precursor cells of mammals (La Cour, I944), and similarly in the pollen grains of certain Tulipa species (Upcott, I939).

In differentiated blood cells, the cytoplasm of red cells is rich in ribose-nucleic acid and presumably likewise in protein : the spindles are never hollow and the chromosomes are evenly and compactly distributed on the plate. In white cells, however, the cytoplasm is low in ribose-nucleic acid and presumably protein : the spindles are hollow and the chromosomes are arranged on the periphery of the plate. It would seem that hollowness is a sign of weakness, for in pernicious anæmia, and in the mouse as a normal condition, the cytoplasm in some white cells is starved; spindle formation breaks 
down and anaphase does not occur. We may therefore be justified in assuming that, in these cells, the granular cytoplasm is deficient in enzymes for conversion of the clear cytoplasm into the fibrous, spindle-forming cytoplasm, or perhaps simply that it is more dilute.

What may be the first step in a similar breakdown is to be found in the pollen grains of Tulipa sylvestris. Here with extreme degrees of hollowness, chromosomes are left off the plate and are found lying in the granular cytoplasm. The degree of hollow spindle in Tulipa is variable, it is emphasised somewhat where the chromosomes have sub-terminal centromeres. It is greatest in the polyploids. No doubt the variability is associated with absence or degree of vacuole formation in unbalanced cells.

\section{THE SYNCHRONISATION OF MITOSIS}

Where thin-walled pollen grains are closely attached in tetrads and even greater associations, as in some orchids, the pollen-grain mitoses are synchronised (Barber, 1942). This is also true under experimental conditions where pollen grains stick together by incompleteness of wall formation. It is true even of chromosomedeficient grains when their cytoplasm is in contact with complementary hyperploid grains (Barber, I94I ; Sax, I942). As Barber suggested, nuclear interaction is presumably responsible for the rigidity of synchronisation, just as it is responsible for the survival of adherent deficient grains.

In Luzula, Malheiros et al. ( I947) claim from their observations that synchronisation is always complete and furthermore that it fairly close between all the grains within an anther. This as we saw earlier is not always the case. How does this difference arise? It may be that in unusual environmental conditions, e.g. colder climate, the co-ordination in timing breaks down. Similarly in the dwarf grains, where further division occurs, the two mitoses are not always in step. This may be due to the completeness of the separation of the cytoplasm following the primary division, or to an upset related to the conditions which prompted further division.

\section{SUMMARY}

I. Dwarf pollen grains of obscure origin, are found to occur in variable proportions in a single clone of Tradescantia bracteata.

2. Their dwarfness is due to inhibited growth midway in development. The cytoplasm is then deficient in protein and does not accumulate ribose-nucleic acid.

3. They are capable of mitosis and invariably show the normal chromosome number, $n=6$. Polarity of the mitosis, however, is deranged and differentiation is not attained.

4. Following temperature shock, these abortive grains may undergo further mitosis, to give four equal-sized nuclei, with the cytoplasm equally partitioned between them. 
5. In two clones of the same species, an analysis has been made of spindle orientation at the second meiotic division. Cell distribution in both clones proved to be closely similar.

6. The literature on pollen-grain development in Angiosperms is reviewed.

7. An explanation for nuclear differentiation is provided. It is shown that differentiation is dependent on a qualitative difference in the cytoplasm surrounding the two nuclei.

8. The generative cell contains clear cytoplasm with little or no ribose-nucleic acid ; the vegetative cell, cytoplasm rich in ribose-nucleic acid, which is apparently essential to growth and other activities.

9. The inequality in distribution of the cytoplasm is attained by movements of the cytoplasm and nucleus which govern the position, direction, and length of the spindle.

Acknowledgments.- The author is indebted to Dr G. D. Darlington, F.R.S., for advice and criticism and to $\mathrm{MrS}$. Muldal for suggestions concerning the measurement of the angles of the spindles at the 2 nd meiotic division.

\section{REFERENCES}

BARBER, H. N. I94I.

Chromosome behaviour in Uvularia.

7. Genet., 42, 223-257.

BARBER, H. N. 1942.

The pollen-grain division in the Orchidacex.

F. Genet., 43, 97-103.

BRUMFIELD, R. T. $194 \mathrm{I}$.

Asymmetrical spindles in the first microspore division of certain Angiosperms.

Amer. F. Bot., 28, 713-722.

CASPERSSON, T. 1940.

On the role of the nucleic acids in the cell.

Proc. 7th Genet. Congr., pp. 85-86.

DARLINGTON, C. D., AND LA COUR, L. F. 1947.

The Handling of Chromosomes. Allen \& Unwin, London.

DARLINGTON, C. D., AND THOMAS, P. T. 1941 .

Morbid mitosis and the activity of inert chromosomes in Sorghum.

P.R.S., B, 130, 127-15o.

DRAHOWZAL, G. 1936 .

Beiträge zur Morphologie und Entwicklungsgeschichte der Pollenkörner.

Österr. Bot. Z., 85, 241-269.

GEITLER, F. 1935 .

Beobacktungen über die erste Teilung im Pollenkorn der Angiospermen.

Planta, 24, 361-386.

HAGERUP, O. $193^{8}$.

A peculiar asymmetrical mitosis in the microspore of Orchis.

Hereditas, 24, 94-96.

HYDÉN, H. 1943.

Protein metabolism in the nerve cell during growth and function.

Acta. Physiol. Scandinav., 6, supp. 1 7, 1-1 36 . 
JOHNSON, G. T., AND PECK, R. E. 1937.

Observations on the development of the male gametophyte in certain monocots. Ann. Mo. Bot. Gard., 24, 161-1 74 .

KOLLER, P. C. 1943 .

The effects of radiation on pollen-grain development, differentiation, and germination.

P.R.S. Edin., B, 5I, 398-429.

LA COUR, L. F. I 1944 .

Mitosis and cell differentiation in the blood.

P.R.S. Edin., B, 62, 73-85.

MAHESHWARI, P. 1931 .

Contribution to the morphology of Albizzia Lebbek.

7. Indian Bot. Soc., IO, 241-264.

MAHESHWARI, P. 1949 .

The male gametophyte of Angiosperms.

Bot. Rev., ${ }_{5} 5$, I-75.

MALHEIROS, N., CASTRO, D., AND CÂMERA, A. 1947.

Cromosomas Sem Centrômero Localizado. O. Caso Da Luzula purpurea Link.

Agronomia Lusitana, 9, 5 1-74.

NEWMAN, I. V. I 934 .

Studies in the Australian acacias, III.

Proc. Linnean Soc. New South Wales, 59, 237-251.

PAINTER, T. S. 1943.

Gell growth and nucleic acids in the pollen of Rhoeo discolor.

Bot. Gaz., I05, 58-68.

SAMUELSSON, G. I9I3.

Studien über die Enwicklungsgeschichte einiger Bicornes Typen.

Svensk Bot. Tidskr., 7, 97-98.

SAX, K. 1935 .

The effects of temperature on nuclear differentiation in microspore development.

7. Arnold Abor., I6, 301-310.

SAX, K. 1937.

Chromosome behaviour and nuclear development in Tradescantia.

Genetics, 22, 523-533.

SAX, K. 1937.

Effects of variations in temperature on nuclear and cell division in Tradescantia. Amer. 7. Bot., 24, 218-225.

SAX, K. $\quad$ I 942.

Diffusion of gene products.

P.N.A.S., 28, 303-306.

SAX, K., AND EDMONDS, H. W. I933-

Development of the male gametophyte in Tradescantia.

Bot. Gaz., 94, 156-163.

SAX, K., AND HUSTED, L. 1936.

Polarity and differentiation in microspore development.

Amer. F. Bot., 23, 6o6-6og. 
UPCOTT, м. 1939.

The external mechanics of the chromosomes. VII. Abnormal mitosis in the pollen grain.

Chromosoma I, I 78-г 90.

VOGLE, E. 1947 .

Untersuchungen über die Tielungsrichtungen in Pollenmutterzellen und bei der Blaualge.

Chroococcus Öster. Bot. Z., 94, I-29.

WODEHOUSE, R. P. $\quad$ r 935 .

Pollen Grains. McGraw-Hill, N.Y.

WULFF, H. D. I933.

Beiträge zur Kenntnis des männlicken Gametophyten der Angiospermen.

Planta, 21, 12-50.

WULFF, H. D., AND MAHESHWARI, P. 1938.

The male gametophyte of Angiosperms (A critical review).

7. Indian Bot. Soc., r7, 11 7-140.

WYLIE, R. B. 1904.

The morphology of Elodea canadensis.

Bot. Gaz., 37, r-22. 
Plate I.-Pollen grain tetrads in Luzula purpurea. Acetic alcohol, iron aceto-carmine. Figs. $1-3, \times 1800$; fig. $4, \times 95^{\circ}$.

FIG. 1.-Pro-metaphase.

Frg. 3.-Nuclear differentiation complete, with the four generative nuclei in the centre.

FIG. 2.-Non-concurrent mitoses.

FIG. 4.-Group of tetrads showing phases of mitosis from metaphase-telophase. The top cell showing the beginning of nuclear differentiation. 

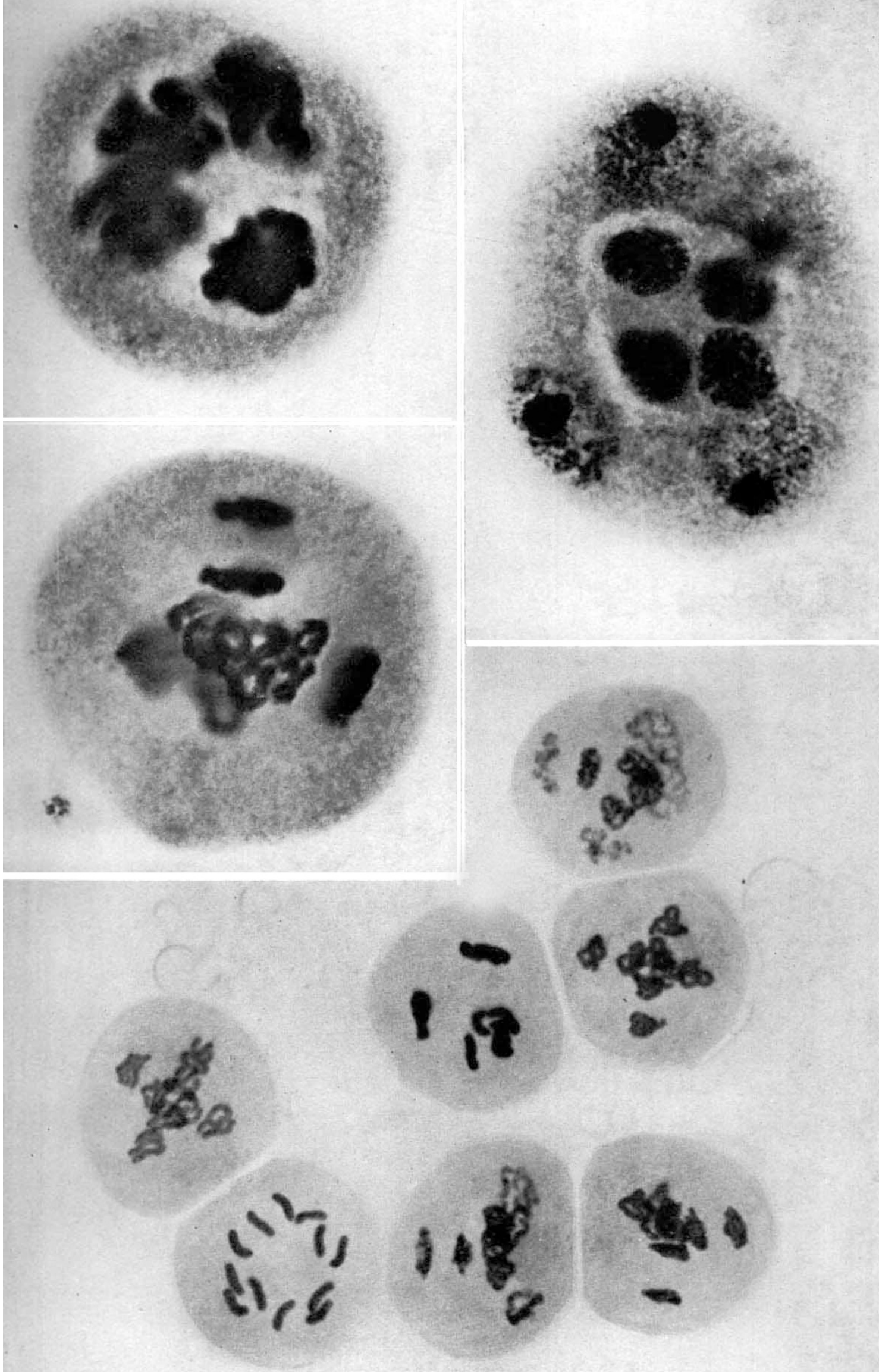
Plate II.-Pollen grains in Tradescantia bracteata (clone 20'). Fixation in acetic alcohol. Figs. 1-3 staining with Feulgen ; 4, 7 and 8 in acetic lacmoid ; 5 in toluidine blue ; 6 with Feulgen and counterstaining in Ponceau red, $\times 1500$ except 5 and $6, \times 1700$.

Fig. 3.--Anaphase in dwarf grain.

FIG. 1.-Anaphase in normal size grain.

FIG. 2.--Early telophase with asymmetrical spindle in normal size grain.

FIG. 5-Weakly charged vegetative nucleus in cytoplasm rich in ribose-nucleic acid; heavily charged generative nucleus in cytoplasm free of ribose-nucleic acid.
FIG. 4.-Normal and dwarf grains showing undifferentiated nuclei in the dwarf grain.

FIG. 7.-Extra mitosis in dwarf grain induced by temperature shock.
FIG. 6.-Partial differentiation of nuclei and cytoplasm.
Fic. 8.-Four equal size nuclei in dwarf grain derived from extra mitosis. 
